Theo kết quả nghiên cứu, góc mặt phẳng hàm dưới ở loại I Angle giảm dần theo tuổi, mức giảm tương ứng của nam là $-0,99 \pm 0,38^{\circ}$, của nữ là $-1,01 \pm 0,39^{\circ}$; phù hợp với nghiên cứu của Ricketts R.M (1996) [1] khi đưa ra nhận xét rằng góc mặt phẳng hàm dưới giảm trung bình 0,5 $\left({ }^{\circ}\right) /$ năm. Tuy nhiên, loại II và III Angle có mức gia tăng theo tuổi, nữ có xu hướng tăng lớn hơn nam, từ 8-9 tuổi có xu hướng tăng lớn hơn từ 78 tuổi nhưng sự khác biệt không có ý nghĩa thống kê.

\section{KẾT LUÂN}

Qua nghiên cứu dọc thực hiện bằng phương pháp đo trên ảnh chuẩn hóa thẳng và nghiêng nhân trắc đầu - mặt trên 206 trẻ em 7 -9 tuổi người Kinh (104 nam, 102 nữ), rút ra kết luận sau: Chiều cao mă̆t toàn bộ, chiều cao tầng mặt dưới, góc mă̆t phẳng hàm dưới giống nhau giữa nam và nữ ở trẻ 7 tuổi, ở loại III lớn hơn loại I và II Angle. Chiêu cao mặt toàn bộ và chiều cao mặt dưới không đổi ở loại I Angle, tăng trưởng đều đăn ở loại II và III Angle từ 7-9 tuổi. Góc mặt phẳng hàm dưới giảm theo tuổi ở loại I Angle, tăng dần theo tuổi ở loại II và III Angle. Nữ có xu hướng tăng trưởng sớm hơn nam.

Lời cảm ơn. Trân trọng cảm ơn những đối tượng tự nguyện tham gia nghiên cứu, cảm ơn sự giúp đõ̃ của Ban giám hiệu trường Tiểu học Liên Ninh, Thanh Trì, Hà Nội. Xin chân thành cảm ơn Viện Đào tạo Răng Hàm Mặt - Đại học Y Hà Nội đã tạo điều kiện cho chúng tôi hoàn thành nghiên cứu này.

\section{TÀI LIÊU THAM KHẢO}

1. Ricketts RM (1996). Progressive cephalometrics paradigm 2000, American Institute for Bioprogressive Education, Scottsdale, Arizona.

2. Platou C, Zachrisson B. U (1983). Incisor position in Scandinavian children with ideal occlusion, Am J Orthod, 83(4), 341-352.

3. Tae Soo Park (1984). A longitudinal cephalometric study of craniofacial growth of Korean children, Korean Journal of Orthodontics, 14(2), 217-231.

4. Hideyuki Kato, Satoshi Fujii (1988). Application of the Ricketts Analysis to Children in the Primary Dentition: Second Report: A Study of Annual Growth, The Japanese Journal of Pediatric Dentistry, 26, 755-768.

5. Lê Võ Yến Nhi, Hoàng Tử Hùng (2011). Sứ tăng trưởng so măt ở trẻ em Việt Nam từ $10-14$ tuổi theo phân tích Ricketts. Y học Thành phố Hồ Chí Minh, 15(2), 21-30.

6. Lê Nguyên Lâm, Nguyễn Bắc Hùng (2014). Sự tăng trưởng của xương hàm dưới ở trẻ từ 12 15 tuổi theo phân tích Ricketts, Tạp chí Y học thực hành, 6(923), 67-71.

7. Pham Cao Phong, Lê Gia Vinh (2016), Sư phát triển và sự xoay của xương hàm dưới lứa tuổi 1112 trên phim sọ nghiêng, Tạp chí Y Học Việt Nam, 453(1), 7-9.

8. Eun-ju Bae (2013). Changes in longitudinal craniofacial growth in subjects with normal occlusions using the Ricketts analysis, The Korean Journal of Orthodontics, 71-79.

\title{
ĐIỀU TRI TIÊU HUYẾT KHỐI TĨNH MACH Ở BÊNH NHÂN NHỒI MÁU NÃO CẤP KHÔNG XÁC ĐİNH CHÍNH XÁC THỜI ĐIỂM KHỞI PHÁT DỰA VÀO MISMATCH DWI - FLAIR TRÊN MRI SỌ NÃO
}

\author{
Nguyễn Thị Hoa ${ }^{1}$, Nguyễn Tiến Dũng ${ }^{2}$, \\ Trần Anh Tuấn ${ }^{2}$, Đào Việt Phương ${ }^{2}$, Mai Duy Tôn ${ }^{2}$
}

\section{TÓM TẮT}

Mục tiêu: Mô tả đặc điểm lâm sàng, hình ảnh học và kết quả điều trị tái tưới máu bằng thuốc tiêu huyết khối đường tĩnh mạch ở bệnh nhân đột quỵ nhồi máu não cấp không xác định chính xác thời điểm khởi phát dựa vào hình ảnh không phù hợp DWI - FLAIR trên phim chụp MRI sọ não. Phương pháp nghiên cứu: Hồi cứu mô tả loạt ca bệnh, theo dõi kết cục lâm sàng

\footnotetext{
${ }^{1}$ Bệnh viện Thanh Nhàn

${ }^{2}$ Bềnh viện Bach Mai

Chịu trách nhiệm chính: Nguyễn Thị Hoa

Email: hoaphuong972008@gmail.com

Ngày nhận bài: 10.6.2021

Ngày phản biên khoa hoc: 3.8.2021

Ngày duyệt bài: 13.8.2021
}

tới 90 ngày sau khởi phát. Đối tượng là các bênh nhân từ 18 tuổi trở lên, đôt quy nhồi máu não cẩp không xác định chính xác thời điểm khởi phát được điều trị bằng thuốc tiêu huyết khối alteplase đường tĩnh mach tại Bệnh viện Bach Mai, đáp ứng yêu cầu khoảng thời gian từ thời điểm cuối cùng bình thường tới khi được tiêu huyết khối trên 4,5 giờ, và khoảng thời gian từ khi được phát hiện đột quỵ tới tiêu huyết khối là dưới 4,5 giờ, có hình ảnh không tương xứng DWI - FLAIR trên phim chup MRI so não, loai trừ những bệnh nhân được chỉ định lấy huyết khối cơ học. Kết quả: Từ tháng 5/2019 tới tháng 5/2021 có 40 bệnh nhân đáp ứng đủ điều kiện nghiên cứu. $72.5 \%$ là nam, tuổi trung bình 67.05 tuối, $75 \%$ được phát hiện đột quy. khi thức giấc. Thời gian trung bình từ lần cuối còn bình thường tới khi được dùng thuốc tiêu huyết khối là 7.75 giờ. Thời gian trung bình từ khi phát hiện đột quy. 
tới khi được dùng thuốc tiêu huyết khối là 3,1 giờ. Điểm NIHSS lúc nhập viện có giá trị trung vị là 6 điểm, điểm NIHSS sau tiêu huyết khối 24 h có gía trị trung vị là 3 điểm. Kết cục lâm sàng sau 90 ngày là $57.5 \%$ bệnh nhân hồi phục tốt (mRS 0-1), 1 bệnh nhân tử vong $(2,5 \%)$, và 4 bệnh nhân cần chăm sóc tại giường (mRS 4-5) chiếm $10 \%$. Tỉ lê xuất huyết nôi so có triệu chứng là $5 \%$. Kết luận: Điều trị tiêu huyết khối bằng alteplase tĩnh mach ở những bênh nhân đột quy nhồi máu não cấp với thời gian khởi phát không xác định dưới hướng dẫn bởi khônng phù hợp DWI - FLAIR trên MRI so não cho kết quả tích cực.

Tư khoá: Đột quy não thức giấc, Nhồi máu não không rõ thời gian khởi phát, không phù hợp DWI FLAIR.

\section{SUMMARY}

THROMBOLYSIS FOR STROKE WITH UNKNOWN TIME OF ONSET WHO HAD MRI FINDINGS OF MISMATCH DWI - FLAIR

Objectives: To describe the clinical, imaging and results of reperfusion therapy with intravenous alteplase thrombolytics in patients with acute ischemic stroke with unknown time of onset based of mismatch between findings on MRI diffusion - weighted imaging and FLAIR. Methods: Retrospective descriptive case series, follow-up clinical outcomes up to 90 days after onset. Subjects were patients aged 18 years or older, acute ischemic stroke with unknown time of onset, treated with intravenous alteplase thrombolytics at Bach Mai Hospital, meeting the requirements of approximately time from last known well to thrombolysis more than 4.5 hours, and time from detection of stroke to thrombolysis less than 4.5 hours, with DWI - FLAIR mismatch on MRI, excluded patients in whom thrombectomy was planned. Results: From May 2019 to May 2021, there were 40 patients who met the study conditions. $72.5 \%$ are male, average age is 67.05 years old. The most frequent reson for an unknown time of onset of stroke symptoms was that the patient had awakened from nighttime sleep with stroke symptoms (75\% ). The median interval between the time that the patient was last known to be well and treatment initiation was 7.75 hours. The median time between symptom recognition and administration of alteplase was 3.1 hours. The median NIHSS score at the time of the baseline examination was 6 points, the mean NIHSS score after $24 \mathrm{~h}$ thrombolysis was 3 points. The favorable outcome (a score of 0 or 1 on the modified Rankin scale) at 90 days in 23 of 40 patients (57.5\%). In the safety population at 90 days, death or an inability to live independently (score on the modified Rankin scale, 4 to 6) occurred in 5 of 40 patients $(12.5 \%)$. Death was reported in 1 patient $(2.5 \%)$. Death was attributed to symptomatic intracranial hemorrhage. The rate of symptomatic intracranial hemorrhage was $5 \%$ (2 patients). Conclusions: Thrombolysis with intravenous alteplase in patients with acute ischemic stroke with unknown time of onset who presented with MRI findings of an ischemic lesion on diffusion - weighted imaging but no clearly visible singnal change in the corresponding region on
FLAIR is positive.

Keywords; Wake-up stroke, Stroke with Unknown Time ò Symptom Onset, DWI-FLAIR mismatch.

\section{I. ĐẠT VẤN ĐỀ}

Đột quy não là nguyên nhân chính gây tử vong hàng thứ 5 tại $M \tilde{y}^{1}$, nguyên nhân gây tử vong hàng thứ 2 trền thế giới ${ }^{2}$. Tại Việt Nam, tỉ lệ bệnh nhân bị đột quỵ não mối năm vào khoảng 90/100.000 dân ${ }^{3}$. Kết cục lâm sàng của bệnh nhân đột quỵ nhồi máu não đã được cải thiện đáng kể với sự ra đời của phương pháp tái tưới máu não bằng thuốc tiêu huyết khối đường tĩnh mạch và can thiệp lấy huyết khối cơ học. Tuy nhiên có một lượng đáng kể khoảng 25\% bệnh nhân khởi phát đột quy không rõ thời gian, phần lớn những bệnh nhân này đã bị loại khỏi các lựa chọn điêu trị này ${ }^{4}$. Một tỉ lệ đáng kể các cơn đột quy sau khi ngủ có thể xảy ra gần với thời gian thức dậy, sẽ nằm trong cửa sổ thời gian để tiêu sợi huyết ${ }^{5}$. Hình ảnh cộng hưởng từ chuỗi xung khuếch tán Diffusion - Weighted Imaging (DWI) là xung nhạy nhất trong chẩn đoán Nhồi máu não, phát hiện sớm nhất sau 11 phút và chắc chắn sau 30 phút nhồi máu não. Trên xung FLAIR, nhồi máu thiếu máu cục bộ xuất hiện dưới dạng tổn thương tăng tín hiệu thường thấy sau $4-6$ h khởi phát đột quy. ${ }^{6}$. Sự không phù hợp DWI - FLAIR xác định bệnh nhân bị đột quỵ thiếu máu cục bộ cấp tính trong vòng 4,5h khởi phát triệu chứng với độ nhạy $62 \%$, độ đặc hiệu $78 \%$, giá trị dự đoán dương tính $83 \%{ }^{7}$. Tính an toàn và hiệu quả của tiêu huyết khối tĩnh mạch ở bệnh nhân đột quy không rõ giờ dựa vào sự không phù hợp hình ành DWI - FLAIR trên phim chụp MRI sọ não đã được chứng minh qua thử nghiệm WAKE UP8. Trên cơ sở đó chúng tôi tiến hành nghiên cứu khảo sát trên các bênh nhân Nhồi máu não cấp không xác định chính xác thời điểm khởi phát được điều trị tái tưới máu bằng thuốc tiêu huyểt khối tĩnh mạch Alteplase dưới hướng dẫn của MRI sọ não (có mismath DWI - FLAIR) nhằm các mục đích.

1. Mô tả đặc điểm lâm sàng, hình ảnh học ở bệnh nhân nhồi máu não cấp không xác định chính xác thời điểm khởi phát được điều trị bằng thuốc tiêu huyết khối đường tĩnh mạch

2. Nhân xét kết quả điều trị tái tưới máu bằng thuốc tiều huyết khối đường tĩnh mạch ở những bệnh nhân trên.

\section{II. ĐỐl TƯỢNG VÀ PHƯƠNG PHÁP NGHIÊN CỨU}

1. Đối tượng nghiên cứu: Các bệnh án của bệnh nhân nhồi máu não cấp được điều trị tái tưới máu bằng tiêu sợi huyết đường tĩnh mạch 
đáp ứng các tiêu chuẩn dưới đây:

Nhồi máu được phát hiện lúc thức giấc hoặc không được chứng kiến, bệnh nhân không thể nhớ chính xác thời điểm khởi phát đột quy.

+Thời gian từ thời điểm cuối cùng bình thường tới khi được tiêu huyết khối 4,5h

+Thời gian từ lúc phát hiện đột quy. tới khi được tiêu huyết khối $<4,5 \mathrm{~h}$

Tuổi từ từ 18 trở lên

Bn có khả năng tự phục vụ bản thân trước đó Có hình ảnh DWI - FLAIR mismatch trên MRI sọ

\section{Tiêu chí loai trù}

Loại khỏi nghiên cứu những bệnh nhân có một trong những tiêu chuẩn loại trừ sau:

Bệnh nhân nhồi máu não đã biết rõ giờ khởi phát

Thời gian LKW - THK < 4,5h.

Những bệnh nhân có chỉ định lấy huyết khối cơ học.

2. Phương pháp nghiên cứu: Nghiên cứu hồi cứu mô tả, cỡ mẫu thuận tiện, thời gian từ tháng $5 / 2019$ tới tháng $5 / 2021$, tại Bệnh viện Bạch Mai. Các mẫu nghiên cứu được thu thập từ bệnh án lưu trữ.Thời gian LKW( last known well) - THK là khoảng thời gian từ lần cuối cùng bệnh nhân được biết là còn bình thường tới khi được dùng thuốc tiêu huyết khối. Thời gian phát hiện - THK là khoảng thời gian bệnh nhân được phát hiên có triêuu chứng đột quy đầu tiên tới khi được dùng thuốc tiêu huyết khối. Kết quả điều trị sớm được đánh giá bằng thay đổi điểm NIHSS sau 1h, 24h, 72h sau tiêu huyết khối. Kết cục lâm sàng được đánh giá bằng thang điểm $\mathrm{mRS}$ (modified Rankin Scale) 90 ngày sau điều trị được thu thập bằng gọi điện thoại cho bệnh nhẩn hoăc người thân của bệnh nhân.

3. Xử lý số liệu: Bằng phần mềm thống kê SPSS phiên bản 20, dữ liệu được trình bày dưới dạng tần số và tỉ lệ phần trăm với biến định tính, dạng trung bình \pm độ lệch chuẩn hoặc trung vị (tứ phân vị) với biến định lượng. So sánh sự khác biệt giữa các nhóm dùng thuật toán Mann Whitney $\mathrm{U}$ test hoặc $\mathrm{T}$ test với biến liên tục và Khi bình phương test bới biến phân loại. Khác biệt có ý nghĩa thống kê khi giá trị kiểm định $\mathrm{p}<0.05$.

\section{KẾT QUẢ NGHIÊN CỨU}

Trong khoảng thời gian từ tháng 5 năm 2019 tới tháng 5 năm 2021, nghiên cứu thu thập được 40 bệnh án có đủ tiêu chuẩn tham gia vào nghiên cứu tại Bệnh viện Bạch Mai

\section{1. Đặc điểm lâm sàng \\ Bảng 1.Đặc điểm chung và lâm sàng lúc vào viện:}

\begin{tabular}{|c|c|c|}
\hline & \begin{tabular}{|c|}
$\begin{array}{c}\text { Nghiên cứu } \\
\text { cúa chúng tôi } \\
(n=40)\end{array}$ \\
\end{tabular} & $\begin{array}{l}\text { Nghiên cứu } \\
\text { WAKE UP } \\
\text { (n= 254) }\end{array}$ \\
\hline $\begin{array}{c}\text { Tuối (Trung bình } \\
\pm \text { SD) } \\
\end{array}$ & $67.05 \pm 13.24$ & $65.3 \pm 11.2$ \\
\hline Nam giới & $29(72.5 \%)$ & $165(65 \%)$ \\
\hline \multicolumn{3}{|c|}{ Thời gian tới lúc THK (giờ) } \\
\hline Phát hiện - THK & $3.1 \pm 0.82$ & $3.1 \pm 0.6$ \\
\hline $\begin{array}{l}\text { Lần cuối bình } \\
\text { thường - THK }\end{array}$ & $7.75 \pm 2.13$ & $10.3 \pm 1.8$ \\
\hline $\begin{array}{l}\text { Điếm NIHSS } \\
\text { (trung vị) }\end{array}$ & $6(4-15)$ & $6(4-9)$ \\
\hline \multicolumn{3}{|c|}{ Lý do không rõ thời gian } \\
\hline $\begin{array}{l}\text { Phát hiên sau } \\
\text { giấc ngủ đêm }\end{array}$ & $30(75 \%)$ & $227(89.4 \%)$ \\
\hline $\begin{array}{l}\text { Phát hiện sau } \\
\text { giấc ngủ ngày }\end{array}$ & $6(16 \%)$ & $12(4.7 \%)$ \\
\hline $\begin{array}{c}\text { Khác (rối loạn } \\
\text { ngôn ngữ, lũ î̃̂̃n) }\end{array}$ & $0 \%)$ & 9\%) \\
\hline \multicolumn{3}{|c|}{ Tiền sử bệnh } \\
\hline Tăng huyết áp & $26(65 \%)$ & $135(53.1 \%)$ \\
\hline Đái tháo đường & $9(22.5 \%)$ & $43(16.9 \%)$ \\
\hline $\begin{array}{l}\text { Rối loạn chuyến } \\
\text { hoá lipid }\end{array}$ & $2(5 \%)$ & $93(36.6 \%)$ \\
\hline Rung nhĩ & $6(15 \%)$ & $30(11.8 \%)$ \\
\hline Tiền sứ đột quy. & $3(7.5 \%)$ & $37(14.6 \%)$ \\
\hline
\end{tabular}

2. Đặc điểm hình ảnh học

Bảng 2. Vị trí tắc mạch:

\begin{tabular}{|c|c|c|}
\hline Vị trí tắc & $\begin{array}{c}\text { Tân suất } \\
(\mathbf{n})\end{array}$ & $\begin{array}{c}\text { Tỉ lệ } \\
(\mathbf{\%})\end{array}$ \\
\hline Không tắc mạch lớn & 30 & 75 \\
\hline Tắc động mạch cảnh trong & 1 & 2.5 \\
\hline Tắc động mạch não giữa M2 & 8 & 20 \\
\hline Tắc động mạch não giữa M1 & 0 & 0 \\
\hline Tắc động mạch não sau & 1 & 2.5 \\
\hline Tắc động mạch thân nền & 0 & 1 \\
\hline
\end{tabular}

Bảng 3. Phân loại nguyên nhân nhồi máu não theo TOAST:

\begin{tabular}{|c|c|c|}
\hline Nguyên nhân & $\begin{array}{c}\text { Tân suất } \\
\text { (n) }\end{array}$ & $\begin{array}{c}\text { Tỉ lệ } \\
(\mathbf{\%})\end{array}$ \\
\hline Bệnh mạch máu lớn & 10 & 25 \\
\hline Bệnh mạch máu nhỏ & 13 & 32.5 \\
\hline Huyết khối từ tim & 4 & 10 \\
\hline Nguyên nhân khác & 0 & 0 \\
\hline Nguyên nhân không xác định & 13 & 32.5 \\
\hline
\end{tabular}

\section{Kết quả điều tri}

Bảng 4. Thay đổi điểm NIHSS sau điều trị tiêu huyêt khối:

\begin{tabular}{|c|c|c|c|c|}
\hline $\begin{array}{c}\text { Điếm } \\
\text { NIHSS }\end{array}$ & $\begin{array}{c}\text { Mean } \\
\text { SD }\end{array}$ & Median & Min & Max \\
\hline $\begin{array}{c}\text { Trước tiêm } \\
\text { Alteplase }\end{array}$ & $7.3 \pm 2.8$ & 6 & 4 & 15 \\
\hline Sau tiêm 1h & $5.2 \pm 2.8$ & 4 & 1 & 12 \\
\hline Sau tiêm 24h $4.5 \pm 5.2$ & 3 & 0 & 27 \\
\hline Sau tiêm 72h & $3.1 \pm 4.7$ & 1 & 0 & 24 \\
\hline
\end{tabular}


Sau 24h tiêu huyết khối có 20 bệnh nhân có giảm điểm NIHSS trên 4 điểm, chiếm $50 \%$, có 3 bệnh nhân tăng điểm NIHSS trên 4 điểm, chiếm $7.5 \%$, có 17 bệnh nhân có thay đổi điểm NIHSS dưới 4 điểm, chiếm $42.5 \%$.

Tỉ lệ xuất huyết nội sọ: có 6 bệnh nhân có xuất huyết nội sọ, chiếm $15 \%$, trong đó có 4 bệnh nhân xuất huyết nội sọ không triệu chứng chiếm $10 \%$ và 2 bệnh nhân xuất huyết nội sọ có triệu chứng chiếm $5 \%$.

Bảng 5. Kêt cưc lâm sàng đánh giá theo thang diê'm modified Rankin (mRS) sau 90 ngày

\begin{tabular}{|c|c|c|}
\hline mRS & $\begin{array}{c}\text { Nghiên cứu của } \\
\text { chúng tôi }\end{array}$ & $\begin{array}{c}\text { Nghiên cứu } \\
\text { WAKE-UP }\end{array}$ \\
\hline 0 & $10(25 \%)$ & $54(21.3 \%)$ \\
\hline 1 & $13(32.5 \%)$ & $82(32.2 \%)$ \\
\hline 2 & $6(15 \%)$ & $54(21.3 \%)$ \\
\hline 3 & $6(15 \%)$ & $31(12.2 \%)$ \\
\hline 4 & $2(5 \%)$ & $18(7 \%)$ \\
\hline 5 & $2(5 \%)$ & $5(2 \%)$ \\
\hline 6 & $1(2.5 \%)$ & $10(4 \%)$ \\
\hline Tống & $\mathbf{4 0 ( 1 0 0 \% )}$ & $\mathbf{2 5 4 ( 1 0 0 \% )}$ \\
\hline
\end{tabular}

\section{BÀN LUÂN}

Tuổi trung bình trong nghiên cứu của chúng tôi là $67.05 \pm 13.04$, tương tự với tuổi trung bình của các nghiên cứu khác như Phạm Phước Sung (2019) là 64.8 tuổi, tuổi trung bình trong nghiên cứu WAKE UP (2018) là $65.3 \pm 11.2$.

Nam là giới chiếm ưu thế trong nghiên cứu của chúng tôi $(72.5 \%)$ cũng như trong hầu hết các nghiên cứu về nhồi máu não, Phạm Phước Sung $(58.59 \%)$, nghiên cứu WAKE UP $(65 \%)$

Thời gian từ khi lần cuối bệnh nhân còn bình thường tới khi được tiêu huyết khối trung bình là $7.75 \pm 2.13$ giờ (WAKE UP là 10.3 giờ), thời gian từ khi bệnh nhân được phát hiện đột quy tới khi được tiêu huyết khối trung bình là $3.1 \pm 0.82$ giờ, tương tự với kết quả của nghiên cứu WAKE UP là 3.1 giờ.

Lý do phổ biến nhất cho thời gian không xác định của các triệu chứng đột quy là bệnh nhân thức giấc sau giấc ngủ ban đêm với các triệu chứng đột quy chiếm $75 \%$ tổng số các bệnh nhân, sau đó là sau giấc ngủ ban ngày chiếm $15 \%$ và các nguyên nhân khác như rối loạn ngôn ngữ hoặc lú lần, không có người chứng kiến và bệnh nhân không có khả năng cung cấp chính xác thời gian khởi phát triệu chứng chiếm $10 \%$. Trong nghiên cứu WAKE UP các tỉ lệ lần lượt là $89.4 \%$ sau giấc ngủ đêm, $4.7 \%$ sau giấc ngủ ngày và $5.9 \%$ với các nguyên nhân khác.

Tiền sử bệnh tật và yếu tố nguy cơ hay gặp nhất là tăng huyết áp, gặp trên $65 \%$ số bệnh nhân. Các yếu tố nguy cơ đột quỵ khác như đái tháo đường gặp trên $22.5 \%$, rung nhĩ $15 \%$, tỉ lệ rối loạn chuyển hoá lipid tương đối thấp, chỉ gặp ở 2 bệnh nhân, tương ứng 5\%.

Nghiên cứu đã loại trừ những bệnh nhân được lên kế hoạch lấy huyết khối cơ học cho nên nhóm bệnh nhẩn nghiên cứu đa phần là những bệnh nhân đột quỵ nhẹ và trung bình với điểm NIHSS vào viện có giá trị trung vị là $6(4-15)$, tương tự với kết quả của nghiên cứu WAKE UP là $6(4-9)$ điểm.

Về đặc điểm hình ảnh học sọ não của nhóm nghiên cứu cho thấy, đa phần bệnh nhân trong nhóm nghiên cứu không có tắc mạch lớn, với 30 bệnh nhân chiếm tỉ lệ $75 \%$. Trong số các bệnh nhân tắc mạch lớn có 8 bệnh nhân tắc mạch não giữa đoạn $M 2$, đa số là các bệnh nhân tuổi cao, tắc đoạn tận $\mathrm{M} 2$, có tuần hoàn bàng hệ tốt nên không có chỉ định lấy huyết khối cơ học.

Mức độ hẹp động mạch cảnh ngoài sọ của nhóm bệnh nhân nghiên cứu tương đối thẩp với $72.5 \%$ là hẹp mức độ không đáng kể hoặc bình thường, chỉ có 1 bệnh nhân tắc hoàn toàn chiếm $2.5 \%$, 1 bệnh nhân hẹp $70-90 \%$ chiếm $2.5 \%$, 5 bệnh nhân hẹp $50-69 \%$ chiếm $12.5 \%$ và 4 bệnh nhân có hẹp dưới $50 \%$ chiếm tỉ lệ $10 \%$.

Phân loại nguyên nhân nhồi máu não theo phân loại TOAST, trong nghiên cứu của chúng tôi nguyên nhân mạch máu nhỏ và nguyên nhân không xác định chiếm tỉ lệ cao nhất với 13 bệnh nhân mỗi nhóm chiếm $32.5 \%$, nguyên nhân mạch máu lớn chiếm tỉ lệ $25 \%$, nguyên nhân huyết khối từ tim chiếm $10 \%$, nhóm nguyên nhân ít gặp khác không thấy xuất hiện trong mẫu nghiên cứu.

Điểm NIHSS trước và sau điều trị 24h là khác biệt có ý nghĩa thống kê với $p=0.006<0.05$. Tỉ lệ giảm điểm NIHSS từ 4 điểm trở lên sau khi tiêm Alteplase chiếm 50\%.

Kết quả điều trị chính được đánh giá bằng kết cục lâm sàng tính theo thang điểm modified Rankin (mRS) 90 ngày sau điều trị, kết quả được cho là thuận lợi khi bênh nhân có khả năng hoạt động độc lập, tương ứng với mRS 0-1 điểm đạt tỉ lệ $57.5 \%$, ở nghiên cứu WAKE UP tỉ lệ này là $53.3 \%$. Tỉ lệ bệnh nhân có kết quả không tốt như tử vong hoặc không có khả năng sống độc lập tương ứng với mRS 4-6 điểm chiếm tỉ lệ $12.5 \%$, ở nghiên cứu WAKE UP tỉ lệ này là $13.5 \%$. Tử vong gặp ở 1 trường hợp chiếm $2.5 \%$.

Xuất huyết chuyển dạng có triệu chứng chiếm tỉ lệ $5 \%$ trong đó 1 bệnh nhân tử vong sau đó và 1 bệnh nhân hiện tại sống phụ thuộc người chăm sóc, mRS 5 điểm. 


\section{KẾT LUẬN}

Lựa chọn những bênh nhân đột quy nhồi máu não cấp không xác định chính xác thời điểm khởi phát có mismatch DWI - FLAIR trên phim chụp MRI sọ não để điều trị tiêu huyết khối tĩnh mạch bằng Alteplase cho thây kết quả hồi phục lâm sàng tốt, mở ra cơ hội cho những bệnh nhân mà trước đây đã bị loại khỏi cơ hội điều trị tái tưới máu do không biết rõ thời gian khởi phát đột quy.

Lời cảm ơn: Chúng tôi xin chân thành cảm ơn lãnh đạo Bệnh viện, Trung tâm Đột Quy và Trung tâm Cấp Cứu Bệnh viện Bạch Mai đã tạo điều kiện thuận lợi để hoàn thành nghiên cứu.

\section{TÀI LIÊU THAM KHẢO}

1. Benjamin EJ, Virani SS, Callaway CW, et al. Heart Disease and Stroke Statistics-2018 Update: A Report From the American Heart Association. Circulation. doi:10.1161/CIR.0000000000000558

2. The top 10 causes of death. Accessed August 8 , 2021. https://www.who int/news-room/factsheets/ detail/ the-top-10-causes-of-death
3. Yamanashi $\mathrm{H}$, Ngoc MQ, Huy TV, et al. Population-Based Incidence Rates of First-Ever Stroke in Central Vietnam. PLOS ONE. 2016; 11(8): e0160665. doi:10.1371/ journal.pone.0160665

4. Mackey J, Kleindorfer D, Sucharew $H$, et al. Population-based study of wake-up strokes. Neurology. 2011;76(19):1662-1667. doi:10.1212/ WNL.0b013e318219fb30

5. Rimmele D, Thomalla G. Wake-Up Stroke: Clinical Characteristics, Imaging Findings, and Treatment Option - an Update. Front Neurol. 2014;5:35. doi:10.3389/fneur.2014.00035

6. Thomalla G, Rossbach P, Rosenkranz M, et al. Negative fluid-attenuated inversion recovery imaging identifies acute ischemic stroke at 3 hours or less. Ann Neurol. 2009;65(6):724-732. doi:10.1002/ana.21651

7. Thomalla G, Cheng B, Ebinger $M$, et al. DWIFLAIR mismatch for the identification of patients with acute ischaemic stroke within $4.5 \mathrm{~h}$ of symptom onset (PRE-FLAIR): a multicentre observational study. Lancet Neurol. 2011; 10(11):978-986. doi:10.1016/S1474-4422 (11)70192-2

8. Thomalla G, Simonsen $\mathbf{C Z}$, Boutitie $\mathbf{F}$, et al. MRI-Guided Thrombolysis for Stroke with Unknown Time of Onset. N Engl J Med. 2018;379(7):611622. doi:10.1056/NEJMoa1804355

\title{
TÌNH TRANG DINH DƯỡNG VÀ MộT Số YẾU TỐ LIÊN QUAN TRÊN BÊNH NHÂN UNG THƯ ĐAI TRỰC TRÀNG TẠI BÊNHH VIỆN THANH NHÀN VÀ BỆNH VIỆN VINMEC TIMES CITY
}

\author{
Nguyễn Văn Trang ${ }^{1}$, Trần Tho Nhị $^{2}$, Nguyễn Hoàng Long ${ }^{3}$
}

\section{TÓM TẮT}

Tình trang dinh dưỡng của bênh nhân ung thư đại trực tràng (UTĐTT) ảnh hưởng đến hiệu quả điều trị, chất lượng cuộc sống và khả năng sống sót của bệnh nhân. Mục tiểu nghiên cứu: Xác định tỷ lệ và một số yếu tố liên quan đến suy dinh dưỡng (SDD) cưa bệnh nhân UTĐTT. Phương pháp nghiên cứu: Nghiên cứu mô tả cắt ngang trên 103 bệnh nhân UTĐTT tại khoa ngoại tổng hợp bệnh viện Thanh Nhàn và khoa ngoại chung bệnh viện Vinmec Times City từ tháng 9/2020 đến tháng 5/2021. Kết quả: Tỷ lệ bệnh nhân có nguyy cơ suy dinh dưỡng hoặc suy dinh dưỡng trước phẫu thuật đánh giá theo thang PGSGA là $85,44 \%$, trong đó SDD nặng chiếm $60,19 \%$ và và thang BMI lần lượt là 19,42\%. Các yếu tố tuổi cao, giới nữ, trình độ học vấn dưới trung học cơ sở và ung thư giai đoạn III và IV có ảnh hưởng tiêu cực đến sinh

\footnotetext{
${ }^{1}$ Bệnh viện đa khoa Vinmec Times City

2Trường Đại học Y Hà Nội

3 Viện Khoa học sức khỏe, Trường Đại học VinUni

Chịu trách nhiệm chính: Nguyễn Văn Trang

Email: V.trangnv1@vinmec.com

Ngày nhận bài: 11.6.2021

Ngày phản biên khoa họ: 2.8.2021

Ngày duyệt bài: 12.8.2021
}

dưỡng bệnh nhân $(p<0,05)$. Trong khi đó các yếu tố về vị trí ung thư, phương pháp điều trị, đường nuôi dưỡng và bệnh viện điều trị không có mối liên quan có ý nghĩa thống kê với tỷ lệ suy dinh dưỡng bệnh nhân ( $p>0,05)$. Kết luâan: Nghiên cứu cho thây bệnh nhân UTĐTT trước phẩu thuật có tỷ lệ SDD cao. Do đó, nhân viên y tế cần chú trọng đến sàng lọc tình trạng suy dinh dưỡng çủa bệnh nhân để đưa ra các biện pháp can thiệp, hỗ trợ kịp thời.

Tư khóa: ung thư đại trực tràng, suy dinh dưỡng, PG-SGA, BMI.

\section{SUMMARY}

NUTRITIONAL STATUS AND SOME FACTORS RELATED TO COLORECTAL CANCER PATIENTS AT THANH NHAN HOSPITAL AND VINMEC TIMES CITY HOSPITAL

Nutritional status of colorectal cancer (CC) patients affects treatment effectiveness, quality of life and patient survival time. Research objective: To determine the prevalence and some factors related to malnutrition of CC patients. Methods: A crosssectional descriptive study on 103 colorectal cancer patients before surgery at the general surgery department of Thanh Nhan hospital and the general surgery department of Vinmec Times City hospital from September 2020 to May 2021. Results: The 